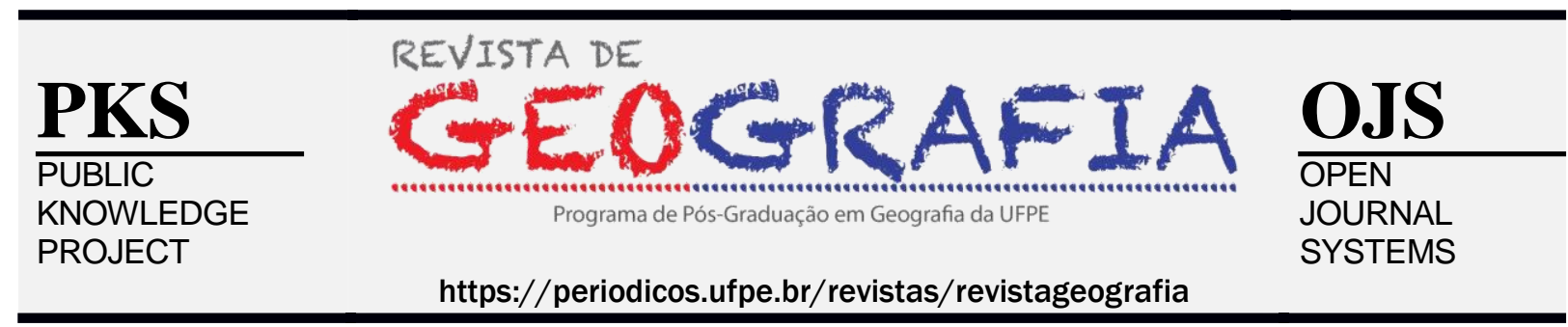

\title{
PROPOSTA DE UTILIZAÇÃO DO GOOGLE EARTH PRO PARA A CONFECÇÃO DE MAPEAMENTO GEOMORFOLÓGICO DE DETALHE DO MACIÇO ESTRUTURAL DE ÁGUA BRANCA (AL / PE)
}

\author{
Larissa Furtado Lins dos Santos ${ }^{1}$, Rhaissa Francisca Tavares de Melo ${ }^{2}$, Danielle \\ Gomes da Silva Listo ${ }^{3}$ \\ ${ }^{1}$ Mestranda pelo Programa de Pós-Graduação em Geografia da UFPE. E-mail: larissa.furtadols@ hotmail.com
${ }^{2}$ Doutora em Geografia pela UFPE. E-mail: rhaissatavares@ hotmail.com
${ }^{3}$ Docente do Programa de Pós-Graduaçãoem Geografia da UFPE. E-mail: dannyavlis@yahoo.com.br
}

Artigo recebido em 13/05/2019 e aceito em 25/11/2019

\begin{abstract}
RESUMO
O processo de construção de mapas está presente há séculos no mundo. Com a finalidade de representar os elementos presentes no espaço, esta atividade acompanhou o desenvolvimento da sociedade, que, por sua vez, impulsionou o progresso da tecnologia, aperfeiçoando cada vez mais as técnicas, sobretudo após o surgimento do computador. Sendo assim, este artigo tem como objetivo principal propor a utilização do software Google Earth Pro para a confecção de mapeamentos geomorfológicos em escala de detalhe, se pretende utilizar novos softwares de manipulação de imagens, a fim de melhorar o processo de confecção destes mapeamentos. Partindo deste pressuposto é elaborada uma análise do processo de confecção e do resultado final, delineando uma comparação entre o mapeamento produzido a partir do Google Earth Pro e outro, finalizado no software ArcGIS na sua versão 10.2.2. A partir disso, é descrita uma análise enaltecendo os principais pontos positivos e negativos acerca da utilização do Google Earth Pro para estes fins.
\end{abstract}

Palavras-chave: Google Earth Pro; ArcGIS; Mapeamento geomorfológico.

\section{PROPOSAL FOR USE OF GOOGLE EARTH PRO FOR THE GEOMORPHOLOGICAL MAPPING DETAIL OF THE ÁGUA BRANCA STRUCTURAL MASS (AL / PE)}

\begin{abstract}
The process of map building has been around for centuries in the world. In order to represent the elements, present in space, this activity accompanied the development of society, which, in turn, boosted the progress of technology, improving techniques more and more, especially after the emergence of the computer. Thus, this article has as main objective to propose the use of Google Earth Pro software for the elaboration of geomorphological mapping in scale of detail, intending to use new software of manipulation of images, in order to improve the process of making these mappings. Based on this assumption, an analysis of the manufacturing process and the final result is elaborated, outlining a comparison between the mapping produced from Google Earth Pro and another, finalized in ArcGIS software version 10.2.2. From this, an analysis is described highlighting the main positive and negative points about using Google Earth Pro for these purposes.
\end{abstract}

Keywords: Google Earth Pro; ArcGIS; Geomorphological mapping. 


\section{INTRODUÇÃO}

A elaboração de mapas temáticos está no cerne da análise espacial há vários séculos. Estes mapas são dotados de informações que corroboram com o entendimento do espaço e suas relações, sendo possível elaborar bases de dados dos mais variados aspectos, dos mais variados ramos de conhecimento. Neste trabalho, em especial, será dissertado acerca da produção do mapeamento geomorfológico em escala de detalhe. Acrescenta-se a este processo de evolução dos mapas, a utilização de imagens de satélite como fornecedoras de dados essenciais para a confecção destes, aumentando de maneira significativa a qualidade e o nível do resultado final. Além disso, a criação de softwares de manipulação de imagens também agregou imenso valor a esta atividade.

É importante salientar que a análise das formas de relevo objetivando a compreensão dos aspectos morfológicos da topografia e da dinâmica responsável pela esculturação da paisagem ganha relevância devido ao auxílio que oferece ao entendimento do modelado terrestre como elemento do sistema natural e condicionante da atividade humana e seus arranjos espaciais. Portanto, o mapeamento das feições geomorfológicas é essencial para a organização e interpretação coerente do território (SILVA, 2005).

A escala de estudo de um determinado relevo deve ser escolhida minuciosamente, pois é a partir desta categoria que o mapeamento deverá ser construído. É a escala de estudo que irá designar as estratégias e técnicas de abordagem da análise geomorfológica (Kohler, 2001). Partindo desta perspectiva, o Google Earth Pro foi o software escolhido para a produção do mapeamento geomorfológico de detalhe do Maciço Estrutural de Água Branca.

O Google Earth é originado do programa Earth View, que foi elaborado pela empresa Keyhole, Inc, uma companhia que em 2004 foi comprada pela Google. No ano 2005 este programa foi renomeado e foi lançado como Google Earth, sendo disponibilizado para uso nos computadores pessoais. Este acontecimento representa um grande símbolo no que diz respeito à disponibilização de imagens derivadas de sensores remotos acoplados em satélites de forma gratuita. Seu surgimento constitui um grande marco na disponibilização das informações espaciais, pois passou de um público restrito para a abertura a todos que possuem o serviço de internet.

Tendo em vista este marco, conforme afirma Lima (2012), por causa da popularização deste software e democratização do acesso à informação geográfica, muitos especialistas o 
consideram como uma das mais marcantes conquistas cartográficas do século XXI. Além disso, é considerado por Allen (2009) uma nova forma revolucionária de observar a Terra.

A sua fácil manipulação, dá margem à uma vasta aplicabilidade tanto em ambiente corporativo, quanto para fins acadêmicos. Esta ferramenta conta com uma interface simples, dotada de inúmeros recursos que auxiliam na visualização e manipulação de imagens de alta resolução (em duas e em três dimensões), além da sua linguagem de fácil acesso. Outras ferramentas disponibilizadas pelo Google Earth, segundo Lopes (2009) são: vetorização de pontos, linhas e polígonos, sobreposição de pontos gerados por outros processos de levantamento, como por exemplo, pontos resultantes de sistemas de posicionamento global por satélite. Contudo, sua utilização em mapeamentos dos mais variados temas ainda aparece de maneira tímida nos trabalhos atuais. Alguns exemplos de trabalhos que utilizaram do Google Earth na confecção de mapeamentos são, segundo Lopes (2009):

- Silva e Nazareno (2009), que utilizaram da tecnologia de Differential Global Positioning System (DGPS) para analisar a precisão de uma imagem de alta resolução presente no banco de dados do Google Earth a partir de pontos levantados em campo que, ao final, comprovou a exatidão das imagens;

- Oliveira et al (2009), que analisaram, a partir de um mosaico elaborado por meio da captura de cenas disponíveis no Google Earth, a exatidão cartográfica das imagens. Foi feito para uso no processo de planejamento ambiental do município de São Leopoldo (RS).

- Wei (2008), que propõe o uso de uma metodologia de uso das imagens do Google Earth associada a pontos de controle em campo e ferramentas CAD a fim de gerar imagens de 1:500, a partir de um software para retificação de imagens. A conclusão desta pesquisa pôde confirmar que os dados das imagens do Google Earth não são compatíveis com esta escala, devido à contradição apresentada pelos dados vetorizados.

- Commandeura e Asperena (2008) utilizaram o banco de dados do Google Earth sobrepondo os dados geográficos da Rijkswaterstaat que, segundo os autores, corresponde à instituição que tem como finalidade gerenciar e administrar as hidrovias da Holanda, na web. A conclusão deste artigo demonstra como consultar e visualizar os dados e ressalta que o uso do Google Earth e o Google Maps está acelerando o desenvolvimento das ferramentas de internet que usam as aplicações de Sistemas de Informação Geográfica (SIG). 
- Hwang (2008) se ocupou em citar exemplos de ApplicationProgramming Interface (API's) que associam o Google Earth (visão em 3D) com o Google Maps (visão em 2D), objetivando a sobreposição de camadas próprias, adicionando o banco da instituição ao banco de dados do Google Earth.

- Gershenzon e Ash (2008) em seu trabalho ressaltam como é dada a distribuição dos dados de sensoriamento remoto na Rússia e citam o Google Earth como exemplo de divulgação destes dados. Além disso, ilustram as possibilidades de uso deste software para sobreposição de dados geográficos, além do seu uso para download de imagens liberadas por órgãos do governo.

Conforme afirma Lima (2012), o Google Earth já foi adotado pelos laboratórios de Geomorfologia e nas ementas dos cursos de algumas Universidades como a Salem State Collegee a Universidade do Tennessee, localizadas nos Estados Unidos (DUNAGAN 2007; HANSON, 2009 in LIMA, 2012). Ainda segundo este autor, já existem trabalhos no Brasil que evidenciam práticas pedagógicas direcionadas ao ensino fundamental, médio e em cursos de Geociências, baseadas na utilização do software, são eles: (RAMOS \& GERALDI, 2002; VOGES \& NASCIMENTO 2009; OLIVEIRA, 2009 apud LIMA, 2012).

Os dados do software são armazenados em formato vetorial Keyhole Markup Language (Linguagem de Marcação de Keyhole - KML), sendo sua extensão representada por: .kml ou .kmz. Segundo Brown (2006) in Lopes (2009), as entidades geométricas deste tipo de armazenamento de imagens podem ser dadas como pontos, linhas, polígonos ou qualquer combinação destes. Pode haver ainda um único arquivo que tenha os três tipos de feições geométricas.

É importante evidenciar que os arquivos em formato Keyhole Markup Language podem conter outros atributos, como como cor, espessura, atributos alfanuméricos, etc., sendo possível unir estas informações às entidades geométricas correspondentes. Desta forma, estes arquivos adquirem consistência, sendo possível a utilização deles para consulta como um Sistema de Informação Geográfica (SIG). A projeção cartográfica utilizada pelo software é WGS84 e a escala do mapeamento geomorfológico de detalhe realizado é de 1:50.000.

Neste sentido, o principal objetivo deste trabalho consiste na produção de um mapeamento geomorfológico de detalhe por meio do Google Earth Pro, evidenciando os pontos positivos e negativos. Esta análise é pautada no processo de confecção e no resultado obtido a partir das ferramentas disponíveis. 


\section{MATERIAIS E MÉTODOS}

\section{Localizaçãoda área de estudo}

A área de estudo abarca o Maciço Estrutural de Água Branca e suas adjacências. É importante salientar que o maciço está localizado em quatro municípios, três deles em Alagoas e somente um em Pernambuco (figura 1), sendo sua maior parte localizada nos municípios denominados Água Branca (AL) e Pariconha (AL) e dividindo porções pequenas entre Inhapi $(\mathrm{AL})$, Mata Grande (AL) e Tacaratu (PE). Está disposto numa área de aproximadamente 400 $\mathrm{km}^{2}$ e uma altitude de cerca de 680 metros em sua porção mais alta. Os seus principais limites são com os seguintes municípios: a norte com Mata Grande e Tacaratu (PE); a sul com Delmiro Gouveia e Olho D'Água do Casado; a leste com Inhapi e Olho D’ Água do Casado; e a oeste com Pariconha. O acesso à área de estudo se dá por meio das rodovias pavimentadas BR-316, BR-101, AL-220, AL-145, sendo o seu principal acesso pela BR 423.

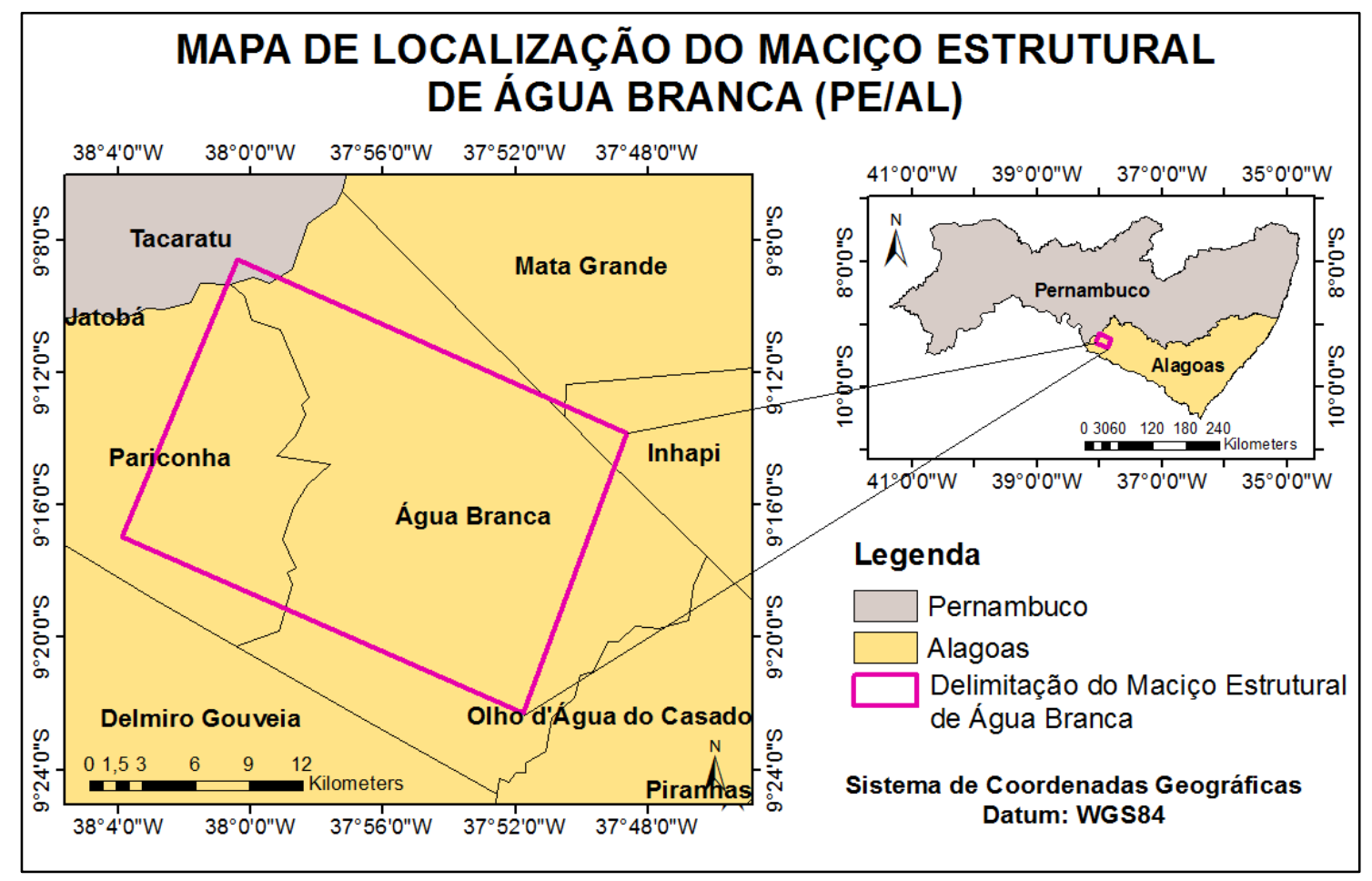

Figura 1: Localização da área de estudo. Fonte: Organizado pelas autoras, IBGE, 2010.

\section{Mapeamento geomorfológico}

O mapeamento geomorfológico foi realizado por intermédio do software Google Earth Pro (que conta com acurácia vertical de 30 metros e horizontal de 90 metros, a partir de dados SRTM com resolução de 1 arco-minuto) e finalizado no ArcGIS, na versão 10.2.2, utilizando a 
metodologia proposta pela Comissão de Mapeamento Geomorfológico de Detalhe da União Geomorfológica Internacional - UGI DEMEK(1972, apud CORRÊA, 1997).

A utilização do Google Earth Pro neste mapeamento teve por finalidade avaliar a qualidade da imagem disponibilizada pelo software (obtida através do satélite Landsat) para estes fins, além do seu processo de confecção. A respeito deste último, é importante frisar a necessidade de o autor conhecer muito bem sua área de estudo, pois neste processo os pontos, polígonos e linhas serão inseridos a partir de sua análise.

Com base nos modelos digitais de elevação e nas atividades de campo realizadas, a área do Maciço Estrutural de Água Branca foi delimitada e dividida em unidades morfológicas, classificadas em modelados de denudação e de acumulação, a partir da altitude e dos aspectos observados nas atividades de campo e na plataforma do Google Earth Pro. Posteriormente, foram sendo inseridos os polígonos referentes à cada porção do mapeamento, divididos em: cimeira a 680 metros, cimeira a 640 metros, encostas sem cobertura, inselbegs, encostas com cobertura, rampas de colúvio, pedimentos a 400 metros, pedimentos a 350 metros e pedimentos a 290 metros. Em seguida foram sendo inseridas as linhas do mapeamento, sendo representadas pelos lineamentos, as planícies e o plaino aluvial.

A posteriori, as linhas e os polígonos que foram salvos em formato $\mathrm{kmz}$ foram transformados para shapefile, a fim de inseri-los na imagem de satélite recortada com os limites do Maciço Estrutural no software ArcGIS 10.2.2.

\section{RESULTADOS E DISCUSSÕES}

O Google Earth Pro correspondeu bem às expectativas iniciais do mapeamento. Sua utilização possibilitou uma análise diferenciada da área de estudo, pois ao longo do processo de construção do mapa é exequível a visualização das feições geomorfológicas por meio de imagens de acurácia vertical de 30 metros e horizontal de 90 metros, gerada através de dados SRTM, com resolução de 1 arco-minuto. Tendo em vista a possibilidade de aproximação da imagem, sua resolução é mantida e a qualidade também, sobretudo após a utilização da ferramenta de extrapolação de relevo, que amplia a visualização das elevações, sendo um aspecto fundamental na análise.

O carregamento das imagens pelo software conta com uma técnica de pirâmide que reduz a resolução e o tamanho da imagem em função do nível de aproximação (zoom) aplicado, formando uma pirâmide da imagem com diferentes tipos de zoom. Esta técnica facilita o 
carregamento da imagem, pois a decompõe em variadas resoluções, otimizando seu carregamento (LOPES, 2009). Ainda segundo o mesmo autor, o software também associa a técnica Quadtree ao processamento de suas imagens. Esta técnica corresponde à divisão de uma imagem em quatro quadrantes, que podem ser divididos em mais quatro e assim por diante, armazenando uma decomposição recursiva do espaço, corroborando com a sua melhor manipulação. Quando associada ao trabalho de campo, agregam informações vitais para um mapeamento rico em detalhes.

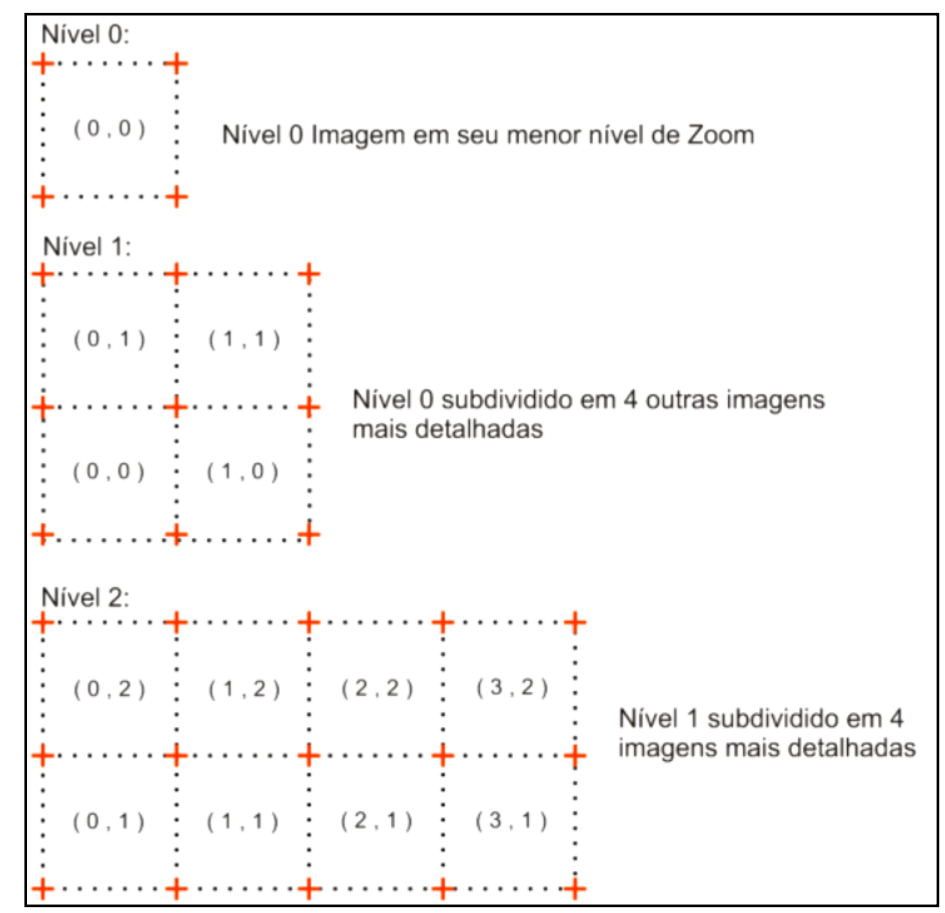

Figura 2: Esquema de disposição das imagens do Google Earth. Fonte: Lopes, 2012.

Além do ponto supracitado, o programa permite a utilização de escalas a partir de 1:25.000, corroborando com a confecção de mapeamentos detentores de grande quantidade de detalhes, o que facilita de maneira significativa a construção e finalização do trabalho. Outro aspecto positivo relacionado à imagem corresponde à aquisição de dados. As imagens disponibilizadas não possuem nenhuma interferência de nuvens, fator que colabora com a visualização da área de estudo. Ademais, a facilidade com a qual as imagens podem ser adquiridas também fortalecem a escolha do Google Earth Pro.

Com as ferramentas utilizadas, o mapeamento realizado através do Google Earth Pro evita as generalizações que possam ser provocadas em outros softwares. Este é um ponto fundamental, pois reitera a autonomia e responsabilidade do pesquisador na confecção do 
mapeamento. Sendo assim, para alcançar melhores resultados faz-se necessário a execução de trabalhos de campo antes da plotagem de dados para a produção do mapa. Destarte, deve-se evidenciar que para utilizar o Google Earth Pro para fins de mapeamento em escala de detalhe, é essencial que o pesquisador conheça muito bem a sua área de estudo.

A gratuidade do Google Earth Pro também é um aspecto que é digno de ser exaltado. A grande maioria dos softwares utilizados para a produção de mapeamentos necessita de uma licença que possui um valor elevado. A divulgação do uso de softwares gratuitos contribui substancialmente com o avanço da ciência nas mais variadas esferas de conhecimento.

O principal ponto negativo da utilização do Google Earth Pro para o mapeamento diz respeito à finalização. Ao concluir a elaboração e salvá-lo na qualidade desejável, com uma resolução superior a 1280x720, foi constatado que quanto maior a resolução do mapeamento for salva, menores ficariam as representações dos elementos do mapa na imagem (figura 3). Por esta razão, foi necessário utilizar o ArcGIS para o inserir os elementos necessários - escala, norte geográfico, título, legenda e dados acerca da imagem utilizada.

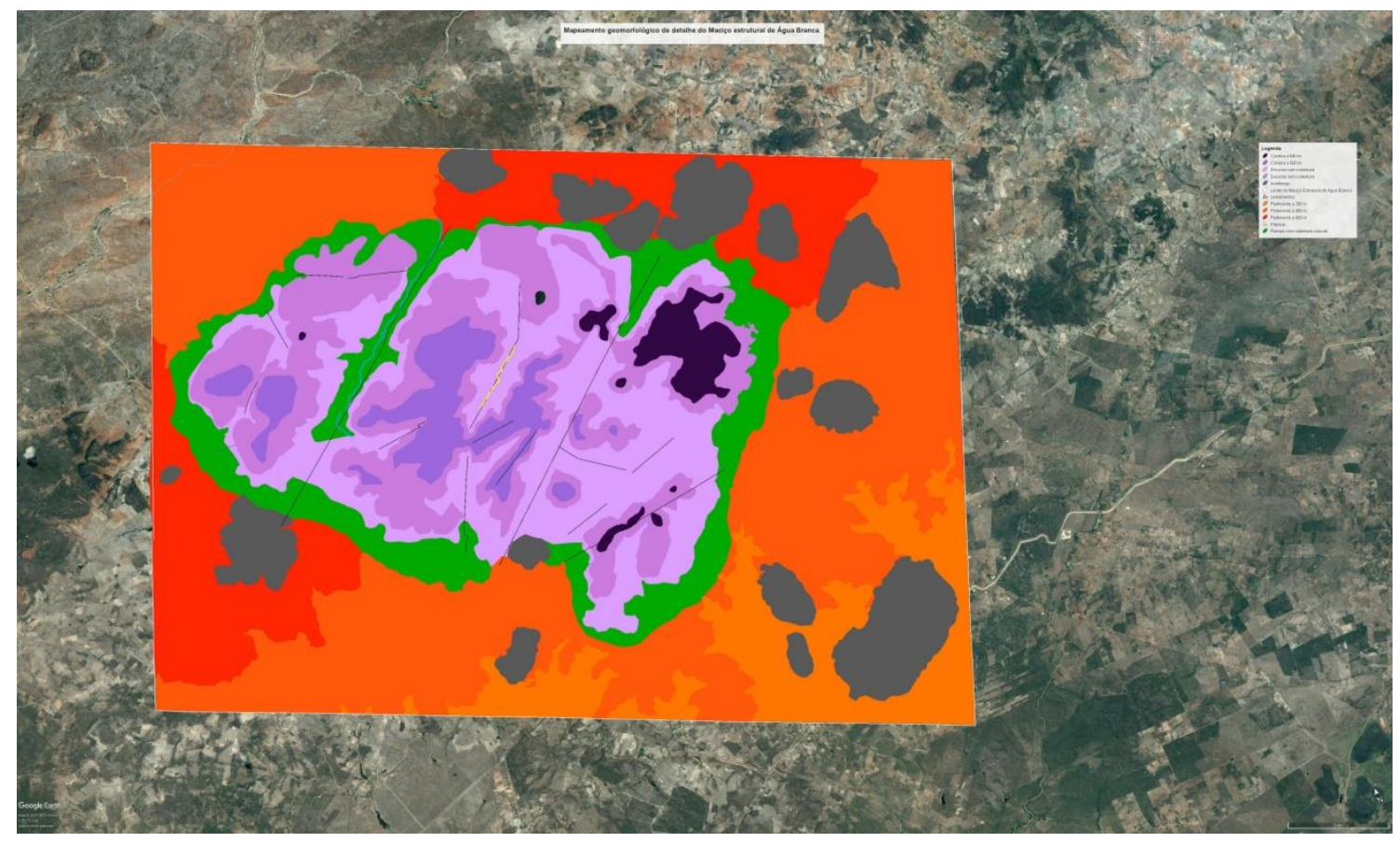

Figura 3: Resultado do mapeamento com a finalização realizada pelo Google Earth Pro. Elaborado pelas autoras.

O software possui uma ferramenta para a inserção das grids (grades) para a visualização das coordenadas geográficas no mapa. Todavia, quando inseridos, os paralelos e meridianos não são facilmente visualizados no mapa com a qualidade máxima (figura 4). 


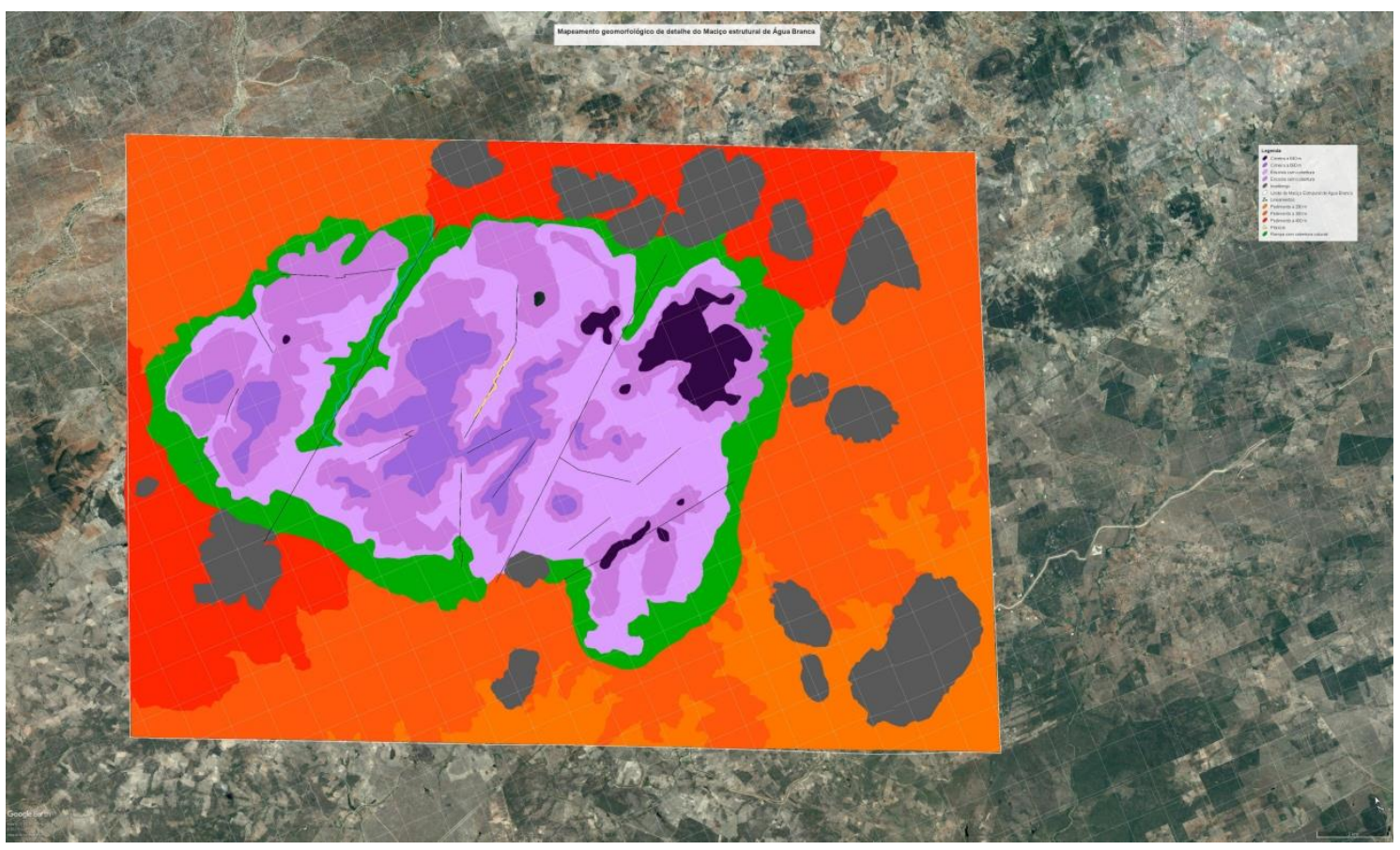

Figura 4: mapeamento geomorfológico de detalhe do Maciço Estrutural de Água Branca finalizado pelo Google Earth Pro com as grids. Elaborado pelas autoras.

Estes pontos negativos foram essenciais para a necessidade da busca de outro software para a finalização do mapeamento. Para suprir esta necessidade, foi utilizado o ArcGIS na sua versão 10.2.2. Sendo assim, a qualidade do resultado final apresentado anteriormente (figura 3) foi comprometida, pois as linhas e os polígonos precisaram ser transformados do formato inicial disponibilizado pelo Google Earth Pro (.kmz) para shapefile (.shp), para que assim o mapa fosse editável no software escolhido para finalização.

Conforme comparação entre as figuras 3 e 5, é possível afirmar que a qualidade do mapa salvo pelo próprio Google Earth Pro é muito melhor do que a imagem final editada e finalizada através do ArcGIS. 


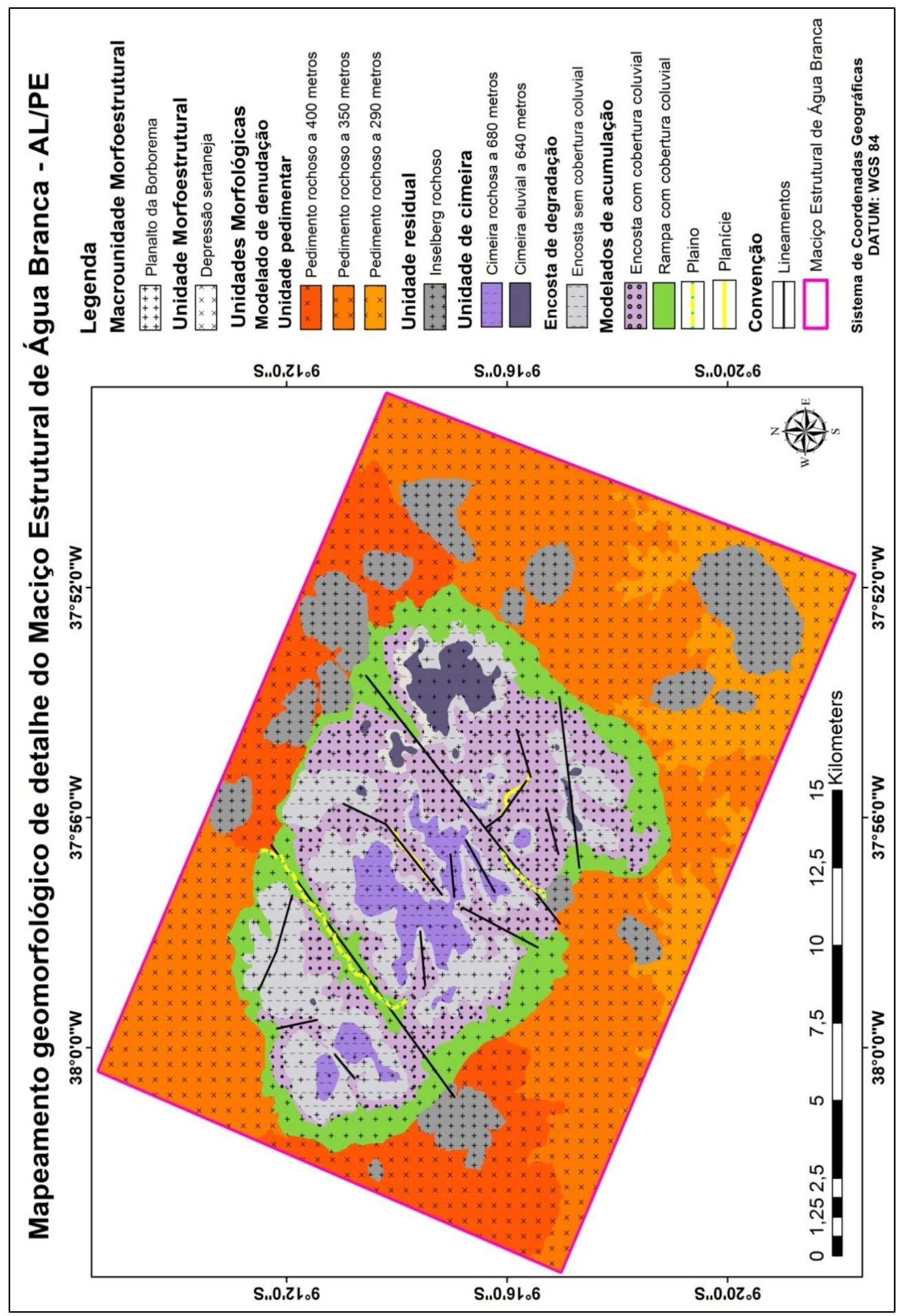

Figura 5: Mapeamento geomorfológico de detalhe do Maciço Estrutural de Água Branca finalizado no ArcGIS. Elaborado pelas autoras. 


\section{CONSIDERAÇÕES FINAIS}

Levando em consideração os aspectos mencionados anteriormente, o Google Earth Pro possui uma excelente qualidade no que diz respeito à resolução da imagem. Esse fator contribui de maneira significativa com a observação do relevo delimitado, bem como possibilita uma excelente visualização em três dimensões do relevo, por meio da ferramenta de extrapolação. A clareza com que os usos da terra são observados também auxiliam na compreensão das unidades morfológicas do Maciço de Água Branca. A correlação com as curvas de nível também constituiu um fator de extrema importância para a construção do mapeamento, sendo preponderante para a delimitação da altitude, facilitando a classificação.

Após apresentar e analisar os resultados do Google Earth Pro e do ArcGIS foi possível concluir que o primeiro dispõe de grande potencial de aplicabilidade para fins de mapeamento. Apesar disso, precisa melhorar nos aspectos associados à finalização da imagem, às cores disponíveis para a inserção no mapeamento, às cores da imagem de satélite e à apresentação das grids no mapa. Caso forem instauradas melhorias ao longo das atualizações, é possível que o Google Earth Pro seja completamente capaz de confeccionar um mapeamento sem necessitar de intermediação de outros softwares.

\section{REFERÊNCIAS BIBLIOGRÁFICAS}

ALLEN, D.Y. A Mirror of Our World: Google Earth and the History of Cartography. MAGERT - ALA Map and Geography Round Table. Coordinates Series B, n. 12,15p, 2009. Disponível em: <http://purl.oclc.org/coordinates/b12.pdf> Acesso em 10 de out de 2017.

BROWN, M. C. Hacking Google Maps and Google Earth. Indianapolis: Wiley Publishing, Inc, 2006.

COMMANDEURA, T. J.; ASPERENA, P. C. M. The effect of Google Earth on the development of a SDI at a government a lagency. In: INTERNACIONAL SOCIETY FORPHOTOGRAMMETRY AND REMOTE SENSING CONGRESS,21., 2008, Beijing. The International Archives Of The Photogrammetry, Remote Sensing And Spatial Information Sciences.

Disponível 
em:<http://www.isprs.org/congresses/beijing2008/proceedings/4_pdf/116.pdf>. Acesso em: 20 jan. 2009.

CORREAA, A. C. B. Mapeamento geomorfológico de detalhe do maciço da Serra da Baixa Verde, Pernambuco: estudo da relação entre a compartimentação geomorfológica e a distribuição dos sistemas geoambientais. 183f. Dissertação de Mestrado - Universidade Federal de Pernambuco, Recife. 1997.

DUNAGAN, S. Integrating Google Earth with geomorphology lab activities and student presentations. 2007 GSA Denver Annual Meeting (28-31 October 2007) Paper No. 56-2, 2007.

GERSHENZON, V.; ASH, E. Experience Of Russian Geoportals Based On Earth Remote Sensing Data. In: INTERNACIONAL SOCIETY FOR PHOTOGRAMMETRY AND REMOTE SENSINGCONGRESS, 21., 2008, Beijing. The International Archives Of The Photogrammetry, Remote Sensing And Spatial Information Sciences.Disponível em:<http://www.isprs.org/congresses/beijing2008/proceedings/4_pdf/151.pdf >. Acesso em 22 jan. 2009.

HWANG, J. T. An Embedded Google Earth/Maps Application onReal Estate Database Inquiry And Display. In: INTERNACIONALSOCIETY FOR PHOTOGRAMMETRY AND REMOTE SENSINGCONGRESS, 21., Beijing. The International Archives Of The Photogrammetry, Remote Sensing And Spatial Information Sciences.2008. Disponível em:<http://www.isprs.org/congresses/beijing2008/proceedings/4_pdf/138.pdf>. Acesso em: 02 fev. 2018.

KOHLER. H. C. A Escala na Análise Geomorfológica. Revista Brasileira de Geomorfologia, v. 3, n. 1, p. 21-23, 2001.

LIMA, R. N. de S. GOOGLE EARTH APLICADO A PESQUISA E ENSINO DA GEOMORFOLOGIA. Revista de Ensino de Geografia, Uberlândia, v. 3, n. 5, p. 17-30, jul./dez. 2012. Disponível em: <www.revistaensinogeografia.ig.ufu.br> Acesso em 07 de out de 2017. 
LOPES, E. E. Proposta Metodológica para Validação de Imagens de Alta Resolução do Google Earth para a Produção de Mapas. Dissertação (Mestrado). Universidade Federal de Santa Catarina - Florianópolis, 2009. 115 p.

OLIVEIRA, M. Z. et al. Imagens do Google Earth para fins de planejamento ambiental: uma análise de exatidão para o município de São Leopoldo/RS. In: SIMPÓSIO BRASILEIRO DESENSORIAMENTO REMOTO, p. 1835-1842, 14. Natal: INPE, 2009.

RAMOS, C.S. \& GERARDI, L.H.O. Cartografia interativa e multimídia: situação atual e perspectivas. In: GERARDI, L.H.O \& MENDES, I.A. (2002) Do Natural, do Social e de suas Interações: visões geográficas. Programa de Pós-Graduação em Geografia - UNESP - Rio Claro-SP. Associação de Geografia Teorética - AGETEO, p.239-250, 2002.

SILVA, Danielle Gomes da. Mapeamento Geomorfológico e Morfoestratigráfico da área de Conceição das Crioulas, Salgueiro - Pernambuco. 71 f. Monografia - Departamento de Ciências Geográficas, Universidade Federal de Pernambuco, 2005.

SILVA, L. A.; NAZARENO, M. R. X. Análise do padrão de exatidão cartográfica da imagem do Google Earth tendo como área de estudo a imagem da cidade de Goiânia. In: SIMPÓSIOBRASILEIRO DE SENSORIAMENTO REMOTO, 14, 2009, Natal. Anais...Natal: INPE, 2009. p. 1723-1730.

VOGES, M. S.; NASCIMENTO, R.S. Práticas pedagógicas e as imagens do Google Earth alguns centros urbanos brasileiros e as questões ambientais. In: II Encontro Iberoamericano de Educação. II Encontro Iberoamericano de Educação. Araraquara, 2007.

WEI, R. Introduce a 1:500 Map Was Made By The Image Of "Google Earth" and Its Software. In: INTERNACIONAL SOCIETY FOR PHOTOGRAMMETRY AND REMOTE SENSING CONGRESS, 21., 2008, Beijing. The International Archives Of The Photogrammetry, Remote Sensing And Spatial Information Sciences. Disponível em:<http://www.isprs.org/congresses/beijing2008/proceedings/3b_pdf/95.pdf >. Acesso em: 02 fev. 2018. 